
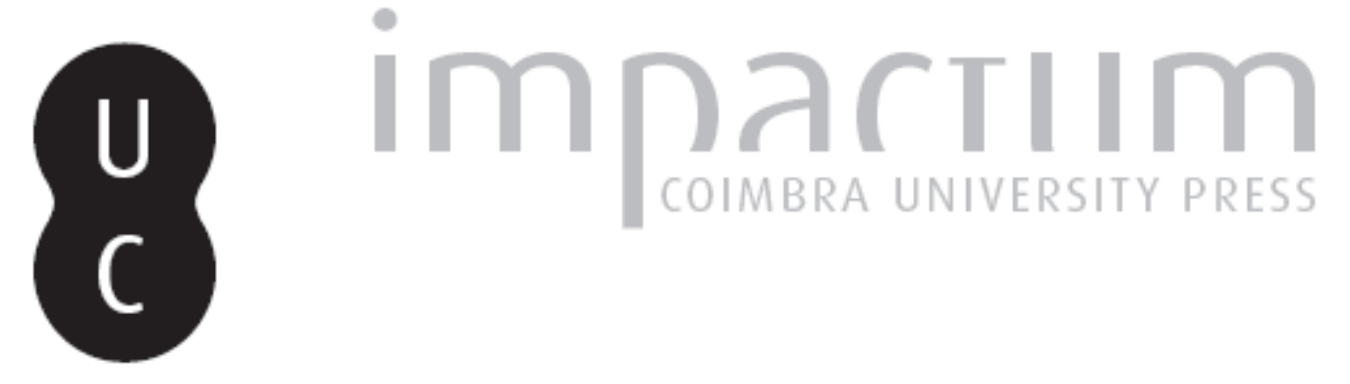

\title{
VI Centenário da Tomada de Ceuta em 21 de Agosto de 1415
}

Publicado por: Imprensa da Universidade de Coimbra

URL

persistente:

URI:http://hdl.handle.net/10316.2/43040

DOI:

DOI:https://doi.org/10.14195/1647-8436_46_47_18

Accessed : $\quad$ 26-Apr-2023 01:29:12

A navegação consulta e descarregamento dos títulos inseridos nas Bibliotecas Digitais UC Digitalis, UC Pombalina e UC Impactum, pressupõem a aceitação plena e sem reservas dos Termos e Condições de Uso destas Bibliotecas Digitais, disponíveis em https://digitalis.uc.pt/pt-pt/termos.

Conforme exposto nos referidos Termos e Condições de Uso, o descarregamento de títulos de acesso restrito requer uma licença válida de autorização devendo o utilizador aceder ao(s) documento(s) a partir de um endereço de IP da instituição detentora da supramencionada licença.

Ao utilizador é apenas permitido o descarregamento para uso pessoal, pelo que o emprego do(s) título(s) descarregado(s) para outro fim, designadamente comercial, carece de autorização do respetivo autor ou editor da obra.

Na medida em que todas as obras da UC Digitalis se encontram protegidas pelo Código do Direito de Autor e Direitos Conexos e demais legislação aplicável, toda a cópia, parcial ou total, deste documento, nos casos em que é legalmente admitida, deverá conter ou fazer-se acompanhar por este aviso. 


\section{BOLETIM DA \\ BIBLIOTECA GERAL DA UNIVERSIDADE DE COIMBRA}

VOL. 46/47 (2015/2016)

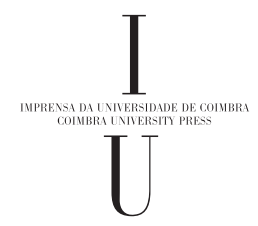




\section{Centenário da Tomada de Ceuta em 21 de Agosto de 1415}

\section{Sala do Catálogo da BGUC, 22 de julho a 4 de setembro de} 2015

ALEXANDRINO, Elvira Amélia Bizarro

A "Crónica da tomada de Ceuta" : sua discordância da "Crónica do Condestabre" : subsídios para a resolução do problema. Coimbra : Ed. do A., 1970. 5-24-61-10

BAEZA HERRAZTI, Alberto

Bulas de cruzada en la reconquista de Ceuta. Ceuta : Caja de Ahorros y Monte de Piedade de Ceuta, 1987.

5-22-41-71

BAEZA HERRAZTI, Alberto, ed. lit.

Ceuta hispano portuguesa : libro colectivo en conmemoración del 575 aniversario de la reconquista de Ceuta por Portugal (21 Agosto 1415) e del 350 aniversario de la Restauración de la monarquía portuguesa (1 Diciembre 1640) en su relación con Ceuta. Ceuta : Instituto de Estudios Ceutíes, 1993. 348 p. (Publicaciones del Instituto de Estudios Ceutíes. Nueva epoca ; 2). 7-61-20 19

BOCAGE, Carlos Roma du, 1853-1918

Étude préliminaire sur la prise de Ceuta par les portugais : le 21 Aout 1415.

Lisboa : Typographia da Cooperativa Militar, 1912. 946.9(64)"14" BOC 
CALADO, Adelino de Almeida, 1930-

O infante D. Fernando e a restituição de Ceuta. Coimbra : Faculdade de Letras da Universidade de Coimbra, 1962. Sep. de: Revista Portuguesa de História. 10.

5-68-43-101

CARRIAZO, Juan de Mata, 1899-1989

La conquista de Ceuta en la Crónica de Juan II de Castilla de Alvar Garcia de Santa Maria. Lisboa : Academia Portuguesa da História, 1982.

6-42-15-115

COSTA, João Paulo Oliveira e ; RODRIGUES, José Damião ; OLIVEIRA, Pedro Aires

História da Expansão e do Império Português. Lisboa : A Esfera dos Livros, 2014.

Coleção particular

DORNELAS, Afonso de, 1880-1944

As armas de Ceuta. Lisboa : Casa Portuguesa, 1925.

5-4-20

DORNELAS, Afonso de, 1880-1944

De Ceuta a Alcácer Kibir em 1923. Lisboa : Casa Portuguesa, 1925.

5-4-21

DORNELAS, Afonso de, 1880-1944

Uma planta de Ceuta. Lisboa : Livraria Ferin, 1913.

IC-18-2-4-110

FARMHOUSE, J.

Subsídio bibliográfico para a história da conquista de Ceuta. Lisboa : Tipografia Universal, 1915.

016:946.9(64)"15" FAR 
FERREIRA, Marino da Cunha Sanches

O sentido europeu e cristão da conquista de Ceuta. Braga : [s.n.], 1958. Sep. de: Revista de Cultura Lusíada da Sociedade Histórica da Independência de Portugal. 18.

5-50-61-74

FREIRE, Anselmo Braamcamp, 1849-1921

Um aventureiro na empresa de Ceuta. Lisboa : Livraria Ferin, 1913.

6-4-9-61

\section{GARCÊS}

A Conquista de Ceuta. Cavaleiro Andante. Lisboa. 104 (26 dez. 1953) [3]. 10-27-14

LIVERMORE, H. V., 1914-2010

On the conquest of Ceuta. [S.I.] : University of Wisconsin Press, 1965.

$5-33-42-27$

LOBATO, Alexandre, 1915-1985

Ainda em torno da conquista de Ceuta. [S.I. : s.n., D.L. 1986] (Lisboa : Tip. Silvas).

5-26-15-176

LOPES, Fernão, 1380?-1460

Crónica de D. João I. Int. de Humberto Baquero Moreno; pref. de António Sérgio. [S. I.] : Livraria Civilização, imp. 1983. 2 v.

$5-22-10-81 / 82$

MASCARENHAS, Jerónimo de

História de la Ciudad de Ceuta : sus sucessos militares y politicos memorias de sus santos [...] escrita em 1648. Pub. sob a dir. de Afonso de Dornelas. Lisboa : Academia das Sciências de Lisboa, 1918.

9-(4)-3-11-15 
MONTEIRO, João Gouveia, 1958- ; COSTA, António Martins, 1964-

1415 : A conquista de Ceuta : O relato empolgante da última grande vitória de D. João I. Lisboa : Manuscrito, 2015.

Coleção particular

OOM, Ana

À conquista de Ceuta. II. André Letria ; rev. técnica Associação de Professores de História. Lisboa : Zero a Oito, 2008.

9-(1)-4-21-31

OSÓRIO, Baltasar

Ceuta e a capitania de D. Pedro de Meneses : 1415-1437. Lisboa : Academia das Ciências de Lisboa, 1933.

9-(4)-3-11-6

PERES, Damião, 1889-1976

Ceuta cercada : um problema cronológico. Coimbra : Instituto de Estudos

Dr. António de Vasconcelos da Faculdade de Letras da Universidade de

Coimbra, 1969. Sep. de: Revista Portuguesa de História. 12 (1969) 293-299. 5-7-34-33

PIMENTA, Alfredo, 1882-1950

Crónica da Tomada de Ceuta. 2. ed. Lisboa : Livraria Clássica Editora, 1964. 5-62-28

PISANO, Mateus de, 1385-14--

Livro da guerra de Ceuta. Vertido em português por Roberto Corrêa Pinto.

Lisboa : Academia das Sciencias de Lisboa, 1915.

9-(4)-3-11-14

RELAÇÃO do sítio que os mouros puseram à Praça de Ceuta. Em cujo sítio empenharão todas as suas forças mas finalmente foram obrigados a se retirarem, com grande glória dos Valerosos habitantes que a defendiam. Lisboa : [s.n.], 1757.

V.T.-6-6-25 
ROSA, Maria de Lurdes Pereira, 1965-

Longas guerras, longos sonhos africanos : da tomada de Ceuta ao fim do Império. 1. ed. Porto : Fio da Palavra, 2010.

10-(1)-7-30-4

SALAS, Javier de

Dos cartas sobre la expedicion a Ceuta en 1415. Coimbra : Imprensa da Universidade, 1931. Sep. de: O Instituto. 81 : 3 (1931).

IC-1-3-8-195

SANCEAU, Elaine, 1896-1978

Os portugueses na empresa de Ceuta. Porto : Edições Marânus, 1962. Sep. de: Boletim Cultural da Câmara Municipal do Porto. Porto. 25 : 3/4 (1962). 5-6-59-112

SANTOS, José Loureiro dos

Ceuta : 1415 : a conquista. Lisboa : Prefácio, D.L. 2002.

$5-57-43$

SERRÃO, Joaquim Veríssimo, 1925-

A conquista de Ceuta no Diário veneziano de António Morosini. In: Actas [do]

Congresso Internacional de História dos Descobrimentos. Lisboa : Comissão

Executiva das Comemorações do V Centenário da morte do Infante D. Henrique, 1961. p. 543-550.

5-68-16

VELOSO, João

A armada de D. João I para a conquista de Ceuta. Cadernos Históricos. Lagos. 4 (ago. 1993) 89-97.

A-18-26-1

ZURARA, Gomes Eanes de, ca. 1410-ca. 1474

Crónica da Tomada de Ceuta. Intr. e notas de Reis Brasil. Mem Martins :

Publicações Europa-América, D.L. 1992.

6-12-69-34 